\title{
Outcome and donor site morbidity of buccal versus lingual mucosal graft in substitution urethroplasty for anterior urethral stricture
}

\author{
Surendra K. Shrivastava*, M. C. Songra, Naraindas Kewlani
}

Department of Surgery, Gandhi Medical College Bhopal, Madhya Pradesh, India

Received: 17 April 2016

Accepted: 03 June 2016

\section{*Correspondence:}

Dr. Surendra K.Shrivastava,

E-mail: drsurendrashrivastava@gmail.com

Copyright: ( ) the author(s), publisher and licensee Medip Academy. This is an open-access article distributed under the terms of the Creative Commons Attribution Non-Commercial License, which permits unrestricted non-commercial use, distribution, and reproduction in any medium, provided the original work is properly cited.

\begin{abstract}
Background: To compare buccal versus lingual mucosal grafts in substitution urethroplasty in terms of surgical outcome and donor site morbidity.

Methods: A total of 50 patients who underwent single stage substitution urethroplasty for anterior urethral stricture from March 2008 to December 2014 were included in the study. Out of these 27 had buccal mucosal graft urethroplasty and 23 had lingual mucosal graft urethroplasty. The patients were compared for surgical outcome and donor site morbidity.

Results: The mean age and stricture length were comparable in the two groups. The surgical outcome was also comparable in the two groups with 3 failures in buccal mucosal group and 2 in lingual mucosal group.

Lingual mucosal graft was easier to harvest but overall donor site complications were comparable in both the groups.

Conclusions: Lingual mucosal graft harvesting is easier and the surgical outcome is comparable to buccal mucosal grafts. The donor site morbidity is comparable to buccal mucosal grafts. Lingual mucosal grafts is especially useful in patients with sub mucosal fibrosis and unhealthy buccal mucosal.
\end{abstract}

Keywords: Substitution urethroplasty, Lingual mucosa, Buccal mucosa

\section{INTRODUCTION}

Urethral stricture disease dates to antiquity. It is a narrowing of urethra caused by spongiofibrosis. The narrowing may initially be asymptomatic but subsequently may lead to restriction of urine flow, dilatation of proximal urethra and in severe cases bladder and renal damage.

Management of urethral stricture has been continuously evolving. Various treatement modalities are urethral dilatation, optical urethrotomy, end to end anastomosis and substitution urethroplasty. Short segment strictures $(<2 \mathrm{~cm})$ have been managed by end to end anastomosis with fairly good results. However in strictures of greater lengths end to end anastomosis leads to chordee and sexual dysfunction and such strictures require substitution urethroplasty.
Various graft materials have been used as substitute to urethral mucosa. Skin graft, bladder epithelial graft and colonic mucosal graft are few amongst these..$^{1-4}$

Currently oral mucosa is unsurpassed as donor substitute material in anterior urethroplasty. Use of buccal mucosa (BM) as a urethral mucosa substitute was first described in 1941 by Humby. ${ }^{5}$ Buccal mucosa is considered the gold standard for substitution urethroplasty. ${ }^{6,7}$ Oral mucosal grafts include buccal graft taken from the inner surface of cheek and lingual graft taken from lateral and under surface of tongue. Lingual mucosa covering the lateral and under surface of tongue is identical to the lining of the rest of the oral cavity morphologically, histologically and immunologically.

Oral mucosa is the preferred substitute not just because of the ease of harvest, compatibility with wet environment, 
easy ingrowth and graft uptake but also because of favourable immunological properties and resistance to infection and also minimal donor site morbidity.

In this study we have compared the outcome of buccal versus lingual mucosal graft in substitution urethroplasty for anterior urethral stricture in terms of patency of urethra post operatively and donor site morbidity.

\section{METHODS}

The study was conducted in the Department of Surgery, Gandhi Medical College, Bhopal with the aim to compare outcome of buccal vs lingual mucosal grafts in substitution urethroplasty. The study included 50 patients who underwent substitution urethroplasty using either buccal mucosal or lingual mucosal grafts from March 2008 to December 2014.

A total of 50 patients were included in the study. The buccal mucosa group (BMG) had 27 patients and lingual mucosa group (LMG) had 23 patients.

\section{Exclusion criteria}

Strictures $<2 \mathrm{~cm}$ in length, very complex strictures and prior failed urethroplasty were excluded. Any patient with prior oral surgery and visible mucosal changes were also excluded.

\section{Pre-operative workup}

A detailed history and examination was done. The investigations included retrograde cystourethrogram and micturating cystourethrogram to evaluate the site and length of stricture, uroflometry and other routine investigations. The surgical procedure used was standard "Barbaglis dorsal onlay graft urethroplasty" technique under spinal and general anesthesia.

Lingual or buccal mucosa was harvested from under surface of tongue and inner surface of cheek respectively from one or both the sides depending on the length desired as shown in Figure 1. The edges of the defect were closed with 3-0 polyglactin suture as given in Figure 2. After proper defattening graft was stretched in length and width and applied to tunica albuginea as a dorsal onlay grafts presented in Figure 3.

A 16 Fr. Silicon catheter was used for stenting the repaired urethra which was removed on day 21. Patients were allowed liquids by evening on day one and soft diet by the second day. Full diet was allowed by day 4 . Postoperatively graft site morbidity was evaluated on the basis of haemorrhage, swelling, pain, numbness, difficulty in mouth opening, paresthesia, difficulty during mastication, slurring of speech, tongue mobility and altered taste sensation.

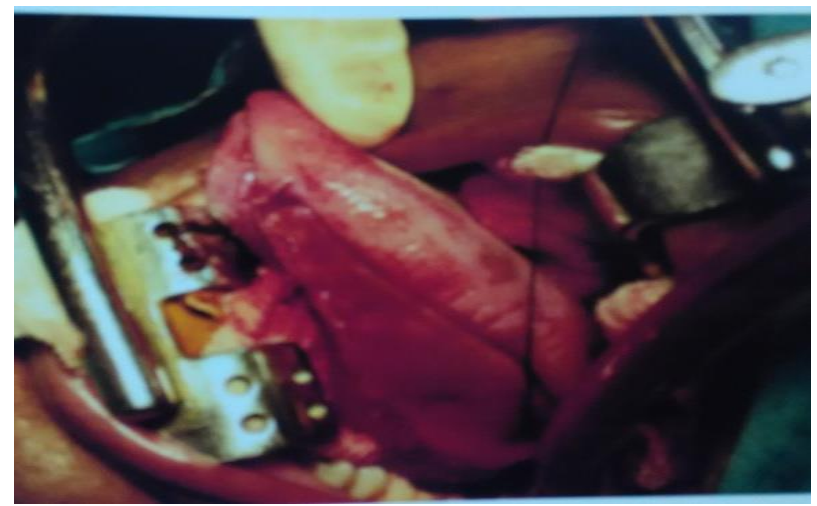

Figure 1: Harvesting lingual mucosal graft.

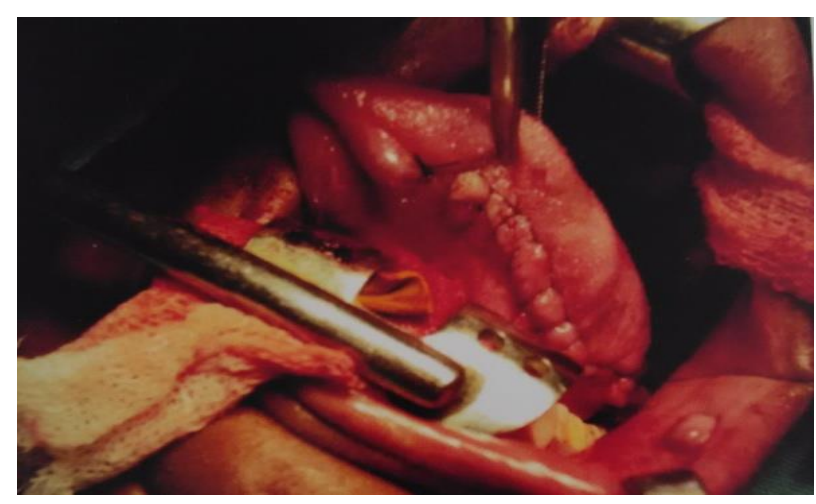

Figure 2: Closure of graft site.

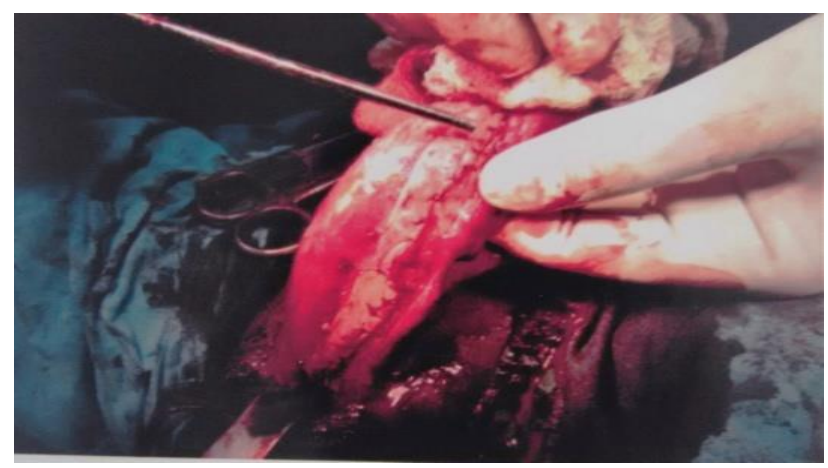

Figure 3: Dorsal onlay graft placement.

Urethral catheter was removed at the end of three weeks and uroflometry was done. Retrograde urethrogram was done at three months. All the patients were followed up at three weeks, three months, six months and at the end of one year. The study was conducted after approval from ethical committee of the institute.

\section{RESULTS}

The mean age in BMG was 28.1 years and in LMG was 32.6 years which were statistically comparable. The average stricture length was $5.1 \mathrm{~cm}$ in BMG and $5.2 \mathrm{~cm}$ in LMG which was comparable. The mean Qmax was $3.39 \mathrm{ml} / \mathrm{sec}$ in $\mathrm{BMG}$ and $4.8 \mathrm{ml} / \mathrm{sec}$ in $\mathrm{LMG}$ as given in 
The most common site for urethral stricture in our study was the penobulbar urethra (Table 1).

Table 1: Patient characteristics.

\begin{tabular}{|lll|}
\hline Patients profile & BM group & LM group \\
\hline Age (years) & $28.1(15-45)$ & $32.6(15-62)$ \\
\hline Stricture length $(\mathrm{cm})$ & $5.1(2.5-8.2)$ & $5.2(3.8-6.4)$ \\
\hline $\begin{array}{l}\text { Mean Qmax (pre-op) } \\
(\mathrm{ml} / \mathrm{sec})\end{array}$ & $3.39(1.4-10)$ & $4.8(2.3-8.4)$ \\
\hline
\end{tabular}

The mean time taken to harvest buccal mucosa was 15 mins and lingual mucosa was 13 mins for unilateral grafts and 22 and $18 \mathrm{mins}$ respectively if bilateral. Harvesting lingual mucosa was easier as tongue could be pulled out. Overall surgical time was comparable in the two groups.

The surgical outcome was considered successful if Qmax was $>20 \mathrm{ml} / \mathrm{sec}$. The average post operative peak flow rate was $22.4 \mathrm{ml} / \mathrm{sec}$ in $\mathrm{BM}$ group and $23.18 \mathrm{ml} / \mathrm{sec}$ in LM group. Three patient $(11 \%)$ had post op Qmax $<20 \mathrm{ml} / \mathrm{sec}$ in BM group while $2(8.6 \%)$ in the LM group. Wound infection was present in 2 patients $(7.4 \%)$ in BM group where as one patient in LM group had wound infections which were managed with higher antibiotics. Wound edema was present in 1 patient in each group. Failure was seen in 3 patients $(11 \%)$ in $\mathrm{BM}$ and 2 patients $(8.6 \%)$ in LM group during follow up with Qmax $<15 \mathrm{ml} / \mathrm{sec}$. One of these patients in BM group had anastomotic site narrowing whereas the rest 2 had graft cicatrisation. Both the patients with failure in LM group had graft cicatrisation. There was no incidence of chordee in either of the groups as shown in Table 2.

Overall urethroplasty outcome was comparable in both the groups.The patients with restricture were managed with optical urethrotomy. Immediate complications at donor site included haemorrhage which was observed in one patient $(4.3 \%)$ in lingual mucosa group and none in buccal mucosal group. Around $80 \%$ patients in both the groups complained of pain in immediate post op period. LMG patients had more difficulty in swallowing, speech and protusion of tongue during the first week as compared to BMG group where as patients in BMG had more difficulty in mouth opening, numbness, twitching and parasthesia as shown in Table 3. These gradually subsided and at the end of six months only 1 patient in BMG had numbness at donor site. Two patients (8.6\%) in LMG complained of slurring of speech at the end of six months. These were the patients in which bilateral lingual grafts were harvested. No patient complained of altered taste sensation.

Table 2: Urethroplasty outcome.

\begin{tabular}{|lll|}
\hline Complication & $\begin{array}{l}\text { Buccal mucosal } \\
\text { graft (No. Of } \\
\text { patients) } 27\end{array}$ & $\begin{array}{l}\text { Lingual mucosal } \\
\text { graft (No. Of } \\
\text { patients) } 23\end{array}$ \\
\hline $\begin{array}{l}\text { Qmax } \\
<20 \mathrm{ml} / \mathrm{sec}\end{array}$ & $3(11 \%)$ & $2(8.6 \%)$ \\
\hline $\begin{array}{l}\text { Wound } \\
\text { infection }\end{array}$ & $2(7.4 \%)$ & $1(4.3 \%)$ \\
\hline Edema & $1(3.7 \%)$ & $1(4.3 \%)$ \\
\hline Resticture & $3(11 \%)$ & $2(8.6 \%)$ \\
\hline Chordee & 0 & 0 \\
\hline
\end{tabular}

In the BMG group there was less difficulty in food intake in patients with unilateral grafts simply because the patient chewed from the opposite side. There was no difficulty in mouth opening at the end of six months but one patient complained of numbness at graft site $(3.1 \%)$. Mean duration of follow up was 1.4 years with longest follow up of 3.5years.

Table 3: Donor site morbidity.

\begin{tabular}{|c|c|c|c|c|}
\hline \multirow[t]{2}{*}{ Complication } & \multicolumn{2}{|c|}{ Buccal mucosal graft(27) } & \multicolumn{2}{|c|}{ Lingual mucosal graft(23) } \\
\hline & At $48 \mathrm{hrs}$ & At 3 weeks & At $48 \mathrm{hrs}$ & At 3 weeks \\
\hline Pain at graft site & $24(88.8 \%)$ & 0 & $20(87 \%)$ & 0 \\
\hline Swelling & $4(14.8 \%)$ & 0 & $2(8.6 \%)$ & 0 \\
\hline Numbness & $3(11 \%)$ & $1(3.7 \%)$ & $2(8.6 \%)$ & 0 \\
\hline Paraesthesia & $3(11 \%)$ & $1(3.7 \%)$ & $1(4.3 \%)$ & 0 \\
\hline Twitching & $2(7.4 \%)$ & 0 & 0 & 0 \\
\hline Problem in mouth opening & $22(81.4 \%)$ & $2(7.4 \%)$ & 0 & 0 \\
\hline Problem in food intake & $19(70 \%)$ & $2(7.4 \%)$ & $19(82.6 \%)$ & $3(13 \%)$ \\
\hline Difficulty in tongue protrusion & 0 & 0 & $13(56.5 \%)$ & $8(34.7 \%)$ \\
\hline Slurring of speech & $20(74 \%)$ & 0 & $21(91.3 \%)$ & $10(43.4 \%)$ \\
\hline Altered taste & 0 & 0 & 0 & 0 \\
\hline
\end{tabular}

\section{DISCUSSION}

Once a stricture always a stricture was the dictum in ancient times. The treatment of urethral stricture has come a long way. Substitution urethroplasty gives excellent results and is the treatment of choice for strictures more than $2 \mathrm{~cm}$ in length. A variety of tissues have been used as substitute and quest for a perfect substitute continues. ${ }^{1-4}$ To start with full thickness skin grafts were used but these led to ballonning, diverticula and restricture and hence were given up. ${ }^{8}$ Bladder mucosa 
served as a very good substitute but it was difficult to harvest and led to increased patient morbidity., 2,9

Buccal mucosa graft was first described by Humby in $1941 .^{5}$ It is a versatile urethral substitute with excellent results and has become gold standard for urethral substitute. Oral mucosa grafts are flexible, easy to harvest and trim and have excellent microvasculature favourable for graft uptake. Furthermore the natural moist location of the oral mucosa in oral environment favours its easy adaptability in the urethral passage thus giving good long term results. It is also suggested to have an infection defence layer denoted by a high concentration of $\operatorname{IgA}$ antibodies and hence is quite resistant to infections. ${ }^{6,7,10-12}$

Use of beetlenut and tobacco chewing is very common in our country and are implicated in causation of submucosal fibrosis. ${ }^{13,14}$ In such patients the buccal mucosa is stiff, unhealthy and not suitable for grafting. Moreover oral complications such as bleeding, haematoma formation, injury to stensen's duct, mental nerve neuropathy can occur at the time of surgery. ${ }^{15-17}$ Long term complications such as oral numbness, salivatory changes, difficulty mouth opening, scar retraction have also been reported. ${ }^{18,19}$

Lingual mucosa i.e. the mucosa covering the lateral and undersurface of tongue is identical in structure to that of the lining of the rest of oral cavity. It is constantly available for grafting with favourable immunological properties and tissue characteristics and also is easy to harvest as the tongue can be pulled out. It is excellent donor sites especially in cases where the buccal mucosa is unhealthy or a greater length is required are. Simonato in his study found lingual mucosa an excellent substitute for urethroplasty. ${ }^{20}$

In our study we found buccal mucosa and lingual mucosa had comparable donor site morbidity.

Pain was the most common complaint in the patients in both the groups in immediate post op period. Chauhan et al found pain in $46 \%$ in BM group and $40 \%$ in LM group. $^{21}$ Sharma et al reported pain in almost all the patients and similar result was found in our study. ${ }^{22}$ Sharma et al found swelling and bleeding more in the buccal mucosa group. We in our study found swelling in $14.8 \%$ of BMG and $8.6 \%$ in LMG. Bleeding was observed in 1 patient $(4.3 \%)$ in LMG. BMG had more difficulty in mouth opening. Similar results were observed by Sharma et al and Chauhan et al in their studies. Difficulty in articulation was more in LMG as expected because tongue participates actively in speech.

Srivastava et al in their study found pain and slurring of speech universally in all patients in immediate post op period. ${ }^{23}$ There was no problem in mouth opening, difficulty in tongue protrusion, salivatory disturbances or numbness in any patient in their study.
Simonato in his study on 8 patients with lingual mucosal urethroplasty found no long term donor site complications. Slight oral discomfort was noted in immediate post op period and 7 of 8 patients had successful urethroplasty. ${ }^{20}$.

In the present study we found that lingual mucosal graft was comparable to buccal mucosal graft in terms of success of urethroplasty and overall donor site complications were also comparable.

The limitation of our study was the sample of just 50 patients. Another limitation was average follow up of around 1 year.

\section{CONCLUSION}

Lingual mucosa is a good substitute for urethroplasty especially in patients with tobacco chewing or submucosal fibrosis and where a greater length of graft is required. It has the same favourable graft properties as buccal mucosa with comparable donor site morbidity. Also harvesting lingual graft is easier as tongue can simply be pulled out and the only limitation is graft width. It may be used along with buccal mucosa in cases requiring greater length or as an alternative to buccal mucosa.

\section{Funding: No funding sources}

Conflict of interest: None declared

Ethical approval: The study was approved by the institutional ethics committee

\section{REFERENCES}

1. Devine PC, Fallon B, Devine CJ. Free full thickness skin graft urethroplasty. J Urol. 1976;116:444-6.

2. Ransley PG, Duffy PG, Oesch IL, Van Oyen P, Hoover D. The use of bladder mucosa and combined bladder mucosa/preputial skin grafts for urethral reconstruction. J Urol. 1987;138:1096-8.

3. $\mathrm{Xu} \mathrm{YM,} \mathrm{Qiao} \mathrm{Y,} \mathrm{Sa} \mathrm{YL,} \mathrm{Zhang} \mathrm{J,} \mathrm{Fu} \mathrm{Q,} \mathrm{Song} \mathrm{LJ.}$ Urethral reconstruction using colonic mucosa graft for complex strictures. J Urol. 2009;182:1040-3.

4. Keating MA, Cartwright PC, Duckett JW. Bladder mucosa in urethral reconstructions. J Urol. 1990;4144:827-34.

5. Humby G. A one-stage operation for hypospadius repair. Br J Surg. 1941;29:84-92.

6. Bhargava S, Chapple CR. Buccal mucosal urethroplasty: Is it the new gold standard? BJU Int. 2004;93:1191-3.

7. Barbagli G, Lazzeri M. Surgical treatment of anterior urethral stricture diseases: brief overview. Int. Braz. J Urol. 2007;33:461-94.

8. Webster GD, Robertson CN. The vascularized skin graft urethroplasty: its role and results in urethral stricture management. J Urol. 1985;133:31-3.

9. Baskin LS, Duckett JW. Mucosal grafts in hypospadias and stricture management. AUA Update Ser XIII. 1994;34 
10. Burger RA, Muller SC, El-Damanhoury H, Tschakaloff A, Riedmiller H, Hohenfellner R. The buccal mucosa graft for urethral reconstruction: a preliminary report. J Urol. 1992;147:662-4.

11. Dessanti A, Rigamonti W, Merulla V, Falchetti D, Caccia G. Autologous buccal mucosa graft for hypospadias repair: an initial report. J Urol. 1992;147:1081-4.

12. Brock JW. Autologous buccal mucosal graft for urethral reconstruction. Urology. 1994;44:753-5.

13. Jayanthi V, Probert CS, Sher KS, Mayberry JF. Oral submucosal fibrosis - a preventable disease. Gut. 1992;33(1):4-6.

14. Sinha RJ, Singh V, Sankhwar SN, Dalela D. Donor site morbidity in oral mucosa graft urethroplasty: implications of tobacco consumption. BMC Urol. 2009;9:15.

15. Wood DN, Allen SE, Andrich DE, Greenwell TJ, Mundy AR. The morbidity of buccal mucosal graft harvest for urethroplasty and effect of nonclosure of graft harvest site on postoperative pain. J Urol. 2004;172:580-3.

16. Barbagli G, De Stefani S. Reconstruction of the bulbar urethra using dorsal onlay buccal mucosa grafts: new concepts and surgical tricks. Indian J Urol. 2006;22:113-7.
17. Pansadoro V, Emiliozzi P, Gaffi M. Buccal mucosa urethroplasty in the treatment of bulbar urethral strictures. Urology. 2003;61:1008-10.

18. Stefan K, Thomas K, Mahmoud O, Axel H, Maurice SM, Peter A. Donor site morbidity in buccal mucosal urethroplasty: lower lip or inner cheek. BJU Int. 2005;96:619-23.

19. Dublin N, Stewart L. An audit of oral complications after buccal/lip mucosal harvest for urethroplasty. BJU Int. 2003;91:22.

20. Simonato A, Gregori A, Lissiani A. The tongue as an alternative donor site for graft urethroplasty: a pilot study. J Urol. 2006;175(2):589-92.

21. Chauhan S, Yadav SS, Tomar V. Outcome of buccal mucosa and lingual mucosa graft urethroplasty in management of urethral strictures: A comparative study. Urol Ann.2016;8(1):36-41.

22. Sharma AK, Chandrashekhar R, Keshavmurthy R, Nelvigi GG, Kamath AJ, Sharma S, et al. Lingual buccal mucosa graft urethroplasty for anterior urethral stricture: A prospective comparative analysis. Int J Urol. 2013;20:1199-203.

23. Srivastava A, Dutta A, Jain DK. Initial experience with lingual mucosal graft urethroplasty for anterior stricture. Med J Armed Forces India. 2013;69:1620.

Cite this article as: Shrivastava SK, Songra MC, Kewlani N. Outcome and donor site morbidity of buccal versus lingual mucosal graft in substitution urethroplasty for anterior urethral stricture. Int Surg J 2016;3:1465-9. 